\title{
A Review of Topologies, Controls, and Applications of Multilevel Inverter
}

\author{
Zheng $\mathrm{Lu}^{\mathrm{a}}{ }^{\text {, Honglin Ouyang }}{ }^{\mathrm{b}}$, Muxuan $\mathrm{XiaO}^{\mathrm{c}}$ \\ College of Electrical and information Engineering of Hunan University , Changsha 410082,China \\ a lucia106@163.com, byhl1405.ouyang@vip.sina.com, 'c459019267@qq.com
}

Keywords: Multilevel inverter, Topology structure, Control strategy, Application, Future trend

\begin{abstract}
Multilevel inverter has the advancements of high output voltage, high output power, output voltage waveform being similar to sinusoidal wave, small variety rate and little EMI. Due to these features, multilevel inverter has wide application prospect in comprehensive treatment of power quality, traction, specialty in high voltage speed modulation field. This paper presents a review of different topologies like diode-clamped inverter (neutral-point clamped), capacitor-clamped inverter (flying capacitor), and cascaded inverter with separate DC sources, control strategies and SVPWM techniques in detail. Applications which the multilevel inverters play a key role presently are generalized. Finally, future development trends are addressed.
\end{abstract}

\section{Introduction}

It is more and more popular for middle high power AC motor speed adjustment technology used in major industrial production such as steel rolling, papermaking, cement plant, coal, railway and ships. The AC motor speed regulating system not only can conserve energy, but also can improve the process conditions, product quality and productivity. Simultaneously the application of middle high voltage high-capacity variable frequency speed control system can reduce the emission of exhaust gas as well, such as city subway, high-speed rail, light rail and electric vehicle. It is a most straightest and effective means to solve the environmental pollution problem. Multilevel inverter has become the research hotspot of power electronic technology field along with the mass applications of multilevel inverter in middle, high frequency control and power system.

The topologies, control methods and industry applications of multilevel inverter are summarized in this paper, and the future trends of it are carried as well.

\section{Topologies of Multilevel Inverter}

Since the neutral point clamped three-level inverter was proposed by Japanese scholar A.Nabae in 1980, three kinds of utility multilevel inverters: diode-clamped topology, flying capacitor topology, and cascaded $\mathrm{H}$ bridge topology were proposed by many scholars after years of research [1]. Fig. 1 shows the three kinds of topology structures.

The diode-clamped multilevel inverter is constructed by a number of diodes in series and the diodes were crossed at switches of positive and negative bridge arms to clamp. There is only one switch of every arm act at one time, and thus the inverter can output multilevel voltage. The disadvantage is that it has the unbalance of capacitor voltage [2]. Similar to diode-clamped multilevel inverter, flying capacitor multilevel inverter makes use of capacitor voltage to clamp. Since the capacitor is introduced, the options of composition voltage are increased, and the options of switching states are more flexible. However the disadvantages are that the size is increasing due to a mass of capacitors, high costs and difficult to package[3]. However for cascaded multilevel inverter it only needs increase the series number of $\mathrm{H}$ bridges and doesn't need clamping diodes and capacitors. So there is no unbalance of capacitor voltage problem. The number of components needed is least with the same voltage level and it is easy to realize the modularization of power device and convenient maintenance. It can enhance the output voltage and reduce the harmonic content conveniently. But the disadvantages are that it needs more independent DC sources and can't realize the four-quadrant operation of drive system[4]. Cascaded multilevel inverter can 
classify into two types: equal DC voltage source and unequal DC voltage source.

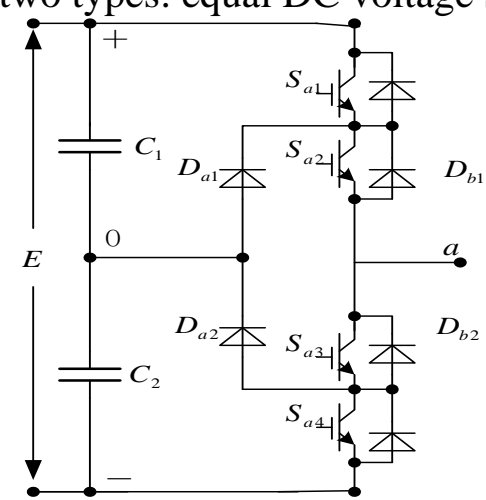

(a) diode-clamped topology

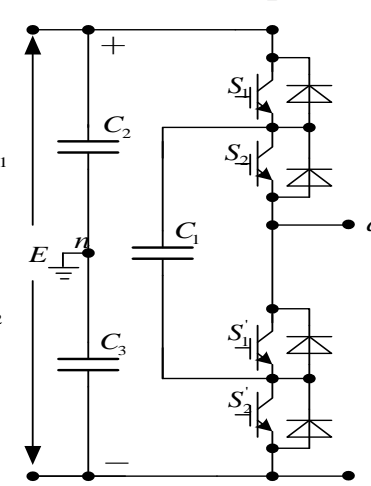

(b)flying capacitor topology

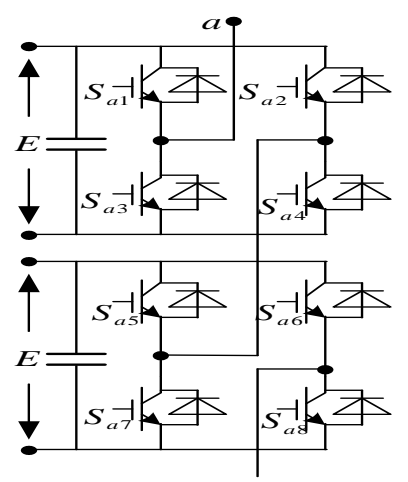

(c) cascaded $\mathrm{H}$ bridge topology

Fig. 1. Three basic topology structures of multilevel inverter

\section{Modulation Method of Multilevel Inverter}

In recent ten years the PWM modulation methods of two-level are expanded to multilevel inverter by scholars and the PWM modulation methods of multilevel inverter have been come into being. The most commonly used modulation methods at present can be divided three classes: carrier PWM (CPWM), selective harmonic elimination PWM (SHEPWM) and space vector PWM (SVPWM). Fig.2 shows the classification of modulation methods, among them the SHEPWM is low switch frequency modulation, the rest are high switch frequency modulation.

CPWM method. There are two ways to generate the multilevel PWM wave in multilevel inverter CPWM method. The first one is triangular carrier phase-shifted PWM. When sinusoidal modulating wave is compared with $\mathrm{N}$ triangle carrier waves which have the same amplitude and frequency but staggered certain angular in phase, it will generate $\mathrm{N}$ PWM waves to control the turn-on and turn-off of switch device belong to $\mathrm{N}$ inverter bridges, then the output waves are superposed and the multilevel waves similar to sinusoidal wave are generated. This method is usually used in cascaded $\mathrm{H}$ bridge multilevel inverter. The second method is called triangular carrier disposition PWM modulation. When sinusoidal modulating wave is compared with multi-triangle carrier waves which have the same amplitude and frequency and are stacked vertical at two sides of horizontal axis, it will generate N PWM waves to control the turn-on and turn-off of switch device belong to $\mathrm{N}$ inverter bridges, then the multilevel waves similar to sinusoidal wave are generated too. This method is usually used in diode-clamped multilevel inverter, and also can apply to other two topologies.

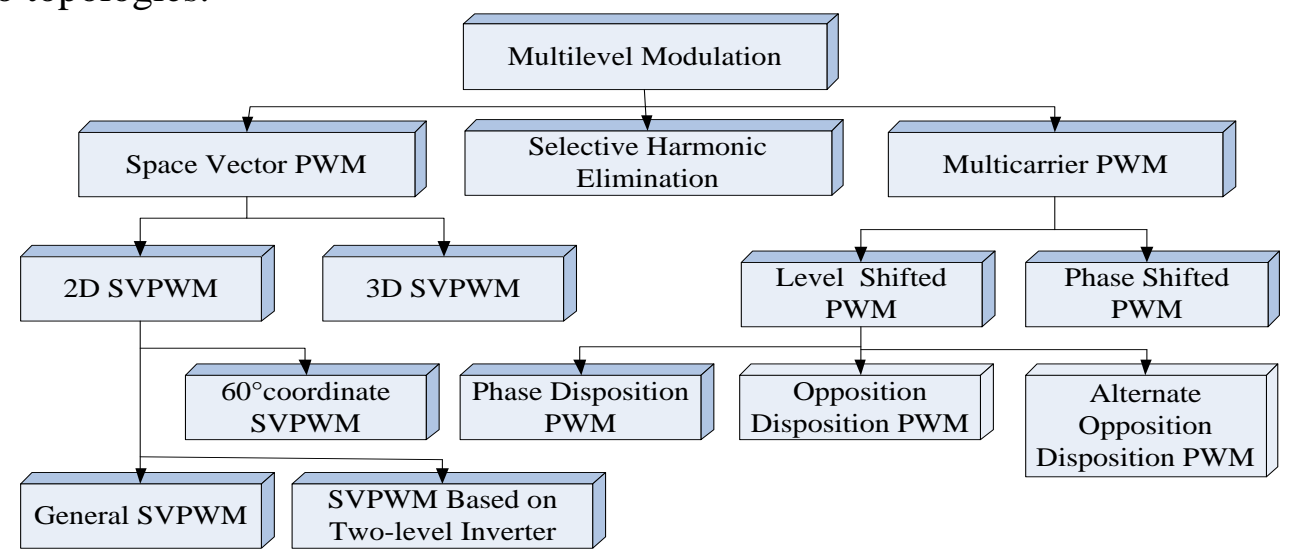

Fig. 2 Multilevel inverter modulation classification

Selective harmonic elimination PWM method.The basic principle of selective harmonic elimination PWM modulation method is that if $M-1$ kinds of harmonics are coming to eliminate, first the amplitude expression of $M-1$ kinds of harmonics can be determined. And set these 
expression equal to zero to solve the values of $M-1$ switching angles $\alpha_{i}$.Since the amplitudes of every order harmonic are functions of switching angles $\alpha_{i}$, in order to eliminate the selected $M-1$ kinds of harmonic contained in output voltage, the switching angles of output voltage waveform are set equal to the value of $\alpha_{i}$ solved above, thus the optimal PWM control is realized [5].

It needs to solve the system of nonlinear equations for selective harmonic elimination PWM modulation method. The requirement of solution convergent is selecting suitable initial value. It is more time-consuming and difficult for real-time compute. However the online solution of nonlinear equations are get more and more easy along with the arising of bulk-storage memory chips and some optimization algorithms and the development of high-speed digital signal processing chips represented for DSP.

SVPWM method.The SVPWM strategy proposed by J.Holtz in1983 regards the AC motor and inverter as a whole, and aims at the round flux trajectory with constant amplitude when AC motor is powered by three-phase symmetry sinusoidal voltage, the flux generated from inverter at real work is taken to approach the round flux trajectory. The turn-on and turn-off of inverter switches are controlled by comparison, and then the PWM waves can be got from the output of inverter. It has advantages such as small torque ripple, low noise, high utilization of DC voltage and easy to implement by DSP. It is widely used in opened loop and closed loop control system. Based on the distribution of voltage vectors it can be classified into two kinds: two-dimension (2D) SVPWM and three-dimension (3D) SVPWM.

(1)2D SVPWM.When there is neither third harmonic nor triple harmonic and the voltage vectors are located in one plane ( $\alpha-\beta$ plane), the SVPWM of multilevel inverter belongs to 2D SVPWM. In traditional 2D SVPWM the calculated amount is large, the complexity of algorithmic is increased with the increasing of level number, and it need trigonometric functional operation, table look-up or coordinate system transformation, all of these will increase the burden of computation. In last decade many 2D SVPWM methods of multilevel inverter which has little calculated amount and complexity were arisen, such as $60^{\circ}$ coordinate SVPWM method[6],general SVPWM method[7],SVPWM method based on two-level inverter [8].

(2)3D SVPWM.If the system is unbalanced or if there is zero sequence or triple harmonics, in this case state vectors are not located in one plane and the SVPWM of multilevel inverter is extending to 3D SVPWM. Now the 3D SVPWM of multilevel inverter has applied in active power filter (APF) successfully.

\section{Application}

In the application of multilevel inverter diode-clamped multilevel inverters are widely used in the drive of traditional high-power AC motor, such as conveyors, pumps, fans, and mills, and provided effective solution for industrial manufacture like oil, gas, metals, power, mining, water, marine, and chemistry. Flying capacitor multilevel inverters are usually used in high bandwidth-high switching frequency applications such as medium-voltage traction drives. Since cascaded H-bridge multilevel inverter has the expandability, and has been used in active filter and reactive power compensation applications, electric and hybrid vehicle, photovoltaic power conversion, uninterruptible power supplies, and magnetic resonance imaging successfully. Fig.3 shows the application of multilevel inverter. 


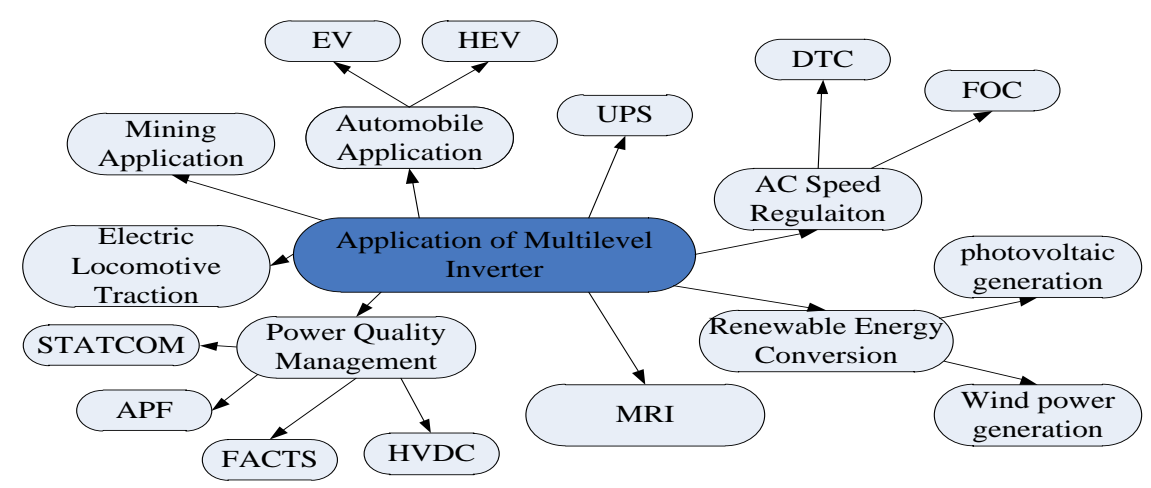

Fig.3 Multilevel inverter applications overview

Application of high-performance high-voltage VVVF.The production and application of high-voltage high power frequency converter are more and more widely along with the production of high voltage large current power electronic device such as SCR,GTO,IGBT,IGCT and the application of series-parallel technology. The using of control methods such as field oriented control (FOC) and direct torque control (DTC) make the performance of VF more optimal.

Application of comprehensive treatment in power quality. It makes the active power filter be suitable for the field of high-capacity and high voltage by using the multilevel invert technology, such as diode clamp multilevel inverter or $2 \mathrm{H}$ bridge cascaded multilevel inverter. In 1996 America scholar F.Z.Peng from Tennessee University made use of $2 \mathrm{H}$ bridge cascaded multilevel inverter into STATCOM, there are N 2H bridge power modules cascaded in AC side constitute each bridge arm, and three bridge arms constitute three phase system by $\mathrm{Y}$ or delta connection. The capacity can reach megavars. Recently in China the scholars developed \pm 20 Mvar STATCOM by multiple overlay the $2 \mathrm{H}$ bridges. It had put into operation in Chaoyang $220 \mathrm{kV}$ substation of the city of Luoyang in Henan province. In addition multilevel inverter can also use in FACTS and HVDC.

Application of renewable energy sources conversion. Cascaded multilevel inverter plays an important role in renewable energy power generation system such as photovoltaic power generation and wind power generation. Because every power cell of cascaded multilevel inverter is powered by isolated DC source, and renewable energy source itself is commendable isolated DC source, it makes cascaded multilevel inverter very suitable to serve as the connector of renewable energy sources and power system.

Application of rail transit traction.The typical application of multilevel inverter variable-frequency speed control system in rail transit system is the traction system of electrified railways. Take electric locomotive as an example, the development process can divide into two periods: DC transmission stage and AC transmission stage. In the last several decades the vast majority of electric locomotive were used DC transmission technology. With the development of electric locomotive manufacturing and power electronic technology, multiple type AC locomotives have been developed. Except electrified railways, electric traction technology is also used in urban railway system.

\section{Development Trend}

From the applications mentioned above it can be seen that multilevel inverter has occupied certain market in the field of high voltage power. The future development trends can be summarized as follow:

Using the wide band gap semiconductor materials power electronics device. Compare to the silicon material power electronics device, Many aspect performances of wide band gap semiconductor materials power electronics device are promoted as an order of magnitude. It is especially suitable for the fields of high voltage power and high temperature, and it is the most ideal and promising power semiconductor material. Now the studies about wide band gap semiconductor power electronics device are focus on $\mathrm{SiC}, \mathrm{GaN}$ and adamas. Along with the constant advance of extract , purify and manufacture technology, power electronics device manufactured by this kind of 
semiconducting material will improve the performance of multilevel inverter greatly.

Application of photoelectric sensor technology. The voltage of high power inverter is often very high. If the high voltage is imported into control circuit for some reason, it will cause the damage of control system and endanger the personal safety. If photoelectric sensor technology is adopted to detect the voltage and current of main circuit, it has the advantages of safe, reliable, good insulativity, small in size and prevents electromagnetic interference. Now this technology has come into practical and commercializes stage. It is a development trend of multilevel inverter by adopting photoelectric sensor technology to detect voltage or current and optical fiber to transmit signal.

Combination of multilevel invert technology and poly-phase machine. In the last decade the poly-phase machine has obtained more and more attention because of the advantages of high reliability, high fault tolerant ability, better torque performance and higher power density. Since it has these advantages it is very suitable for propelling system of ships or naval vessels. In this application field a series of superiority will come into being with the combination of multilevel invert technology and poly-phase machine. Studies and simulations show that the increase of multilevel inverter output level can improve the current and torque pulsation of poly-phase machine.

Using the multilevel inverter on distributed power generation system (DG). DG system has the advantages such as small investment, flexible generation manner, compatibility to environment, it is operating with large power grid widely and increasingly, and it has brought huge change to the operation and control of modern power system. It has become irresistible development tendency for new power system to strive to develop DG technology. However in order to integrate the interconnect several power grids,power grids with different voltage level which is generated by variety renewable energy sources,even coadjacent energy storage systems or grid compensation system into one large scale system, it must adopt the intelligent grid structure which can run on higher voltage and power range and both the efficiency and power supply quality are satisfying the requirements, the complex structure required by power grid and system flexibility have posed great challenge to traditional convertor topological structure.

Development towards fault diagnosis and intelligent modularization direction. The modularize product of multilevel inverter has been developed and put into application at present. Along with the power electronic device developing towards modularization, integration, intelligentization direction, it is combined with DSP and MCU, which make the hardware circuit more and more simplify and disposing digit operational capability more and more better. The application of intelligent control algorithm make the control of multilevel inverter more flexible, and it can realize complicated control rule. All these will make it possible for multilevel inverter to have self-fault diagnostic capability, protect and monitor function and realize the system intelligentization. The modularization and intelligentization of multilevel inverter will become the developmental inexorable trend in future.

\section{Summary}

Multilevel inverter has matured gradually from a new technique and has established the important position in high voltage and high power application. In recent years new model, control strategy and modulation method have been proposed and promoted the technical improvement of multilevel inverter. Now the topology of multilevel inverter has prominent merits in power quality, power range and modularization aspects. The new technique developed recently such as the conversion of renewable energy sources, distribution power generation system have exploited an enormous application fields. Therefore it has reason to believe that the technology has the expansive prospect in power application of nowadays and future. 


\section{References}

[1] Peng, Fang Z., Wei Qian, and Dong Cao. "Recent advances in multilevel converter/inverter topologies and applications.” Power Electronics Conference (IPEC), 2010 International. IEEE, Michigan ,USA (2010), 492-501.

[2] Marchesoni, Mario, and Pierluigi Tenca. "Diode-clamped multilevel converters: a practicable way to balance DC-link voltages.”Industrial Electronics, IEEE Transactions on, Vol. 49, No. 4, (2002)752-765.

[3] Escalante, Miguel F., J-C. Vannier, and Amir Arzandé. "Flying capacitor multilevel inverters and DTC motor drive applications."Industrial Electronics, IEEE Transactions on ,Vol.49,No.4 , (2002)809-815.

[4] Lezana, Pablo, José Rodríguez, and Diego A. Oyarzún. "Cascaded multilevel inverter with regeneration capability and reduced number of switches."Industrial Electronics, IEEE Transactions on, Vol. 55,No.3, (2008) 1059-1066.

[5] Li Li, Dariusz Czarkowski, Yaguang Liu et al. "Multilevel selective harmonic elimination PWM technique in series-connected voltage inverters". IEEE Transactions on Industry Applications, Vol. 36, No. 1, (2000) 160-170.

[6] Zhao Hui, Li Rui, Wang Hong-jun, Yue You-jun ."Study on SVPWM method based on $60^{\circ}$ co ordinate system for three-level inverter”. Proceeding of the CSEE, Vol. 28, No. 24, (2008) 39-45.

[7] Kartick Chandra Jana ,Sujit Kumar Biswas, Parasuram Thakura. “A simple and generalized space vector PWM control of cascaded H-bridge multilevel inverters". 2006 IEEE International Conference on Industrial Technology, Mumbai,Dec. 2006, pp.1073-1078.

[8] Amit Kumar Gupta,and Ashwin M. Khambadkone. “A general space vector PWM algorithm for multilevel inverters, including operation in overmodulation range”. IEEE Transactions on power electronics, vol. 22, no. 2, (2007)517-526. 